\title{
ATRIBUTOS DE VALORACIÓN Y DISPOSICIÓN A PAGAR POR CAFÉ CON DENOMINACIÓN DE ORIGEN DE VERACRUZ, MÉXICO ${ }^{32}$
}

\author{
$\underline{\text { Anastacio Espejel }}^{a *}$, Ariadna Barrera ${ }^{a}$, Magaly Ubaldo ${ }^{a}$ \\ ${ }^{a}$ Universidad Autónoma Chapingo, Texcoco, Estado de México, México (aespejelg@chapingo.mx).
}

El café es un producto que ha viajado por todo el mundo, las primeras tiendas del aromático se encontraron en Venecia, alrededor de 1645; a América llego a Brasil y se extendió por diversos países, entre ellos, México, al cual llegó en el siglo XIX de Cuba. Varios estados mexicanos producen café de altura, entre ellos, Veracruz, quien tiene denominación de origen desde el año 2000; pese a su calidad, el café no ha alcanzado el precio y valor adecuado para los productores. El objetivo, fue identificar atributos de valoración y la mayor disposición a pagar por café de Veracruz. Se diseñó una encuesta mediante el formulario forms de Google y se aplicó a 280 consumidores de café. Se realizo un análisis de significados de compra y regresiones logísticas. Los resultados sugieren que los consumidores otorgan mayores significados a categorías como hedonismo, atributos de calidad, presentación del producto y proceso. La mayor disposición a pagar (DAP) se obtuvo para café de origen mexicano $(20 \%)$, producido por pequeños productores $(16 \%)$, orgánico $(14 \%)$ y con denominación de origen $(11.5 \%)$. Se concluye que los consumidores valorizan el café por atributos tangibles y la mayor (DAP) fue para café mexicano y de pequeños productores.

Palabras clave: valoración contingente, alimento tradicional, significados de compra.

\section{Introducción}

La producción del café en su mayoría se realiza por campesinos (pequeños productores). La cafeticultura mexicana está conformada por unas 500 mil familias cafetaleras, casi un $85 \%$ de estas familias son personas de 25 pueblos indígenas, y México es de los pocos países productores que todavía tienen producción de café arábiga con sombra diversificada, la cual ayuda a conservar la biodiversidad y coadyuva a la protección de la salud de las cuencas hidrográficas (Bernal, 2020). México presenta una crisis, según Ortega \& Ramírez (2013) debido a la presencia del hongo de la roya y la plaga de la broca, el envejecimiento de los cafetales, la falta de programas y de políticas públicas efectivas, así como los bajos precios internacionales del café. Situación que induce a los productores de café a abandonar la actividad para migrar a otras actividades económicas más rentables. El país mantiene un esquema muy rígido en materia de estándares voluntarios de sostenibilidad y poco hace en materia de promoción de la cultura de la calidad en taza, lo cual limita su participación en el creciente y rentable mercado de los cafés especiales (Muñoz-Rodriguez et al., 2019). Por otra parte, pese a que el café de esta región tiene denominación de origen, se observa una escasa valorización y preferencia por los consumidores nacionales lo cual indica que esta distinción no esta cumpliendo con su objetivo.

\section{Objetivo}

Identificar atributos de valoración y la mayor disposición a pagar por café de Veracruz, México.

\section{Metodología}

Se aplicó una encuesta en línea mediante el formulario Google forms a 260 consumidores de café; la encuesta contenía los siguientes apartados: a) datos generales, b) consumo de café, c) influencia en la compra de café, y d) disposición a pagar.

Con la información recopilada se les pidió a los participantes que escribieran tres palabras que evocaban al leer la frase, Café de Veracruz, las palabras fueron corregidas y se eliminaron frases compuestas. Con la lista de palabras se realizó una agrupación en dos campos sociales: 1 . Personas originarias del municipio, 2. Personas ajenas al municipio, posteriormente fueron categorizadas por interpretación personal del investigador. Se calculó el índice de rareza el cual refleja la relación entre el número de palaras diferentes y el número total de palabras para cada estimulo, y el índice de rareza explicando la proporción de palabras citadas una sola vez, denotas hápax, dividido entre el número de palabras diferentes evocadas según Rodrigues, et al.,(2015).

Para la disposición a pagar se realizó una pregunta dicotómica para cada aseveración evaluada: ¿Estaría dispuesto a pagar un sobreprecio (\%) por un café con Denominación de Origen?, ¿Estaría dispuesto a pagar

\footnotetext{
${ }^{32}$ Proyecto 21225-C-68 financiado con fondos de la Dirección General de Investigación y Posgrado de la Universidad Autónoma Chapingo.
} 
un sobreprecio (\%) por un café con certificaciones?, ¿Estaría dispuesto a pagar un sobreprecio (\%) por un café producido por pequeñas organizaciones?, ¿Estaría dispuesto a pagar un sobreprecio (\%) por un café mexicano por uno extranjero? y ¿Estaría dispuesto a pagar un sobreprecio (\%) por un café orgánico?. Posteriormente se aplicó una regresión logística, considerando la variable dicotómica de disposición a pagar como variable dependiente y como variables independientes: a) características socio demográficas (escolaridad, ingreso mensual y lugar de origen), b) Influencia en la compra de café (premios y certificaciones, la certificación brinda mayor calidad, un café con denominación de origen me da sentido de pertenencia a mi nación y es importante conocer el origen del café que consumo), c) calificación de la importancia de las características al consumir café (producido local o regionalmente, producido por pequeños productores, que cuente con denominación de origen, la calidad, el precio) y d) calificación de los atributos del café producido en el municipio ( empaque, sabor, aroma y precio). Los datos obtenidos fueron procesados en el software XLSTAT utilizando un modelo Logit estimado por máxima verosimilitud (Cameron \& Huppert, 1989);(Loureiro \& Hine, 2002).

\section{Resultados}

\subsection{Análisis conceptual}

La participación de los hombres fue mayor que el de las mujeres, el $43.92 \%$ del total de encuestados tienen estudios de nivel superior, no se registró ningún jubilado, pero los empleados no de gobierno fueron los más participativos, el 48.65\% recibe ingresos que oscilan de \$1,501 a \$5,000 (Cuadro 1).

\begin{tabular}{|c|c|c|c|}
\hline \multirow[t]{2}{*}{ CARACTERÍSTICAS } & \multicolumn{3}{|c|}{ CAMPO SOCIAL } \\
\hline & $\begin{array}{c}\text { TOTA } \\
\text { L }\end{array}$ & $\begin{array}{l}\text { Ixhuatlán } \\
\text { Veracruz }\end{array}$ & $\begin{array}{l}\text { Otro origen de } \\
\text { residencia }\end{array}$ \\
\hline \multicolumn{4}{|l|}{ GÉNERO (\%) } \\
\hline Masculino & 62.16 & 41.22 & 20.95 \\
\hline Femenino & 37.84 & 27.70 & 10.14 \\
\hline \multicolumn{4}{|l|}{ ESCOLARIDAD $(\%)$} \\
\hline Básica & 12.84 & 4.73 & 8.11 \\
\hline Media & 14.86 & 12.16 & 2.70 \\
\hline Media superior & 24.32 & 20.95 & 3.38 \\
\hline Superior & 43.92 & 28.38 & 15.54 \\
\hline Posgrado & 4.05 & 2.70 & 1.35 \\
\hline \multicolumn{4}{|l|}{ OCUPACIÓN (\%) } \\
\hline Trabaja por su cuenta & 27.70 & 20.95 & 6.76 \\
\hline Empleado de gobierno & 18.24 & 14.19 & 4.05 \\
\hline Labores del hogar & 4.73 & 3.38 & 1.35 \\
\hline Empleado no de gobierno & 31.76 & 18.92 & 12.84 \\
\hline Jubilado & 0.00 & 0.00 & 0.00 \\
\hline Estudiante & 17.57 & 11.49 & 6.08 \\
\hline \multicolumn{4}{|c|}{$\begin{array}{l}\text { INGRESO MENSUAL APROX. } \\
(\%)\end{array}$} \\
\hline$\$ 1-\$ 1,500$ & 27.70 & 20.95 & 6.76 \\
\hline$\$ 1,501-\$ 5,000$ & 48.65 & 34.46 & 14.19 \\
\hline$\$ 5,001-\$ 10,000$ & 7.43 & 2.03 & 5.41 \\
\hline Mayor de $\$ 10,000$ & 16.22 & 11.49 & 4.73 \\
\hline
\end{tabular}

Cuadro 1. Características sociodemográficas de los participantes (\%) 
Globalmente se asociaron 444 palabras al termino "Café de Ixhuatlán del Café". El campo social 2 tuvo mayor Índice de rareza que el campo social 1, al igual en el Índice de diversidad (Cuadro 2). Las palabras generadas fueron agrupadas en 9 campos semánticos integradas bajo conciencia del experimentador.

Cuadro 2. Parámetros evaluados para el término "Café de Ixhuatlán del Café" por campo social

\begin{tabular}{lccccc}
\hline \multicolumn{1}{c}{ Campo social } & Total de & Número & Hápax & Índice de & Índice de \\
palabras & $\begin{array}{c}\text { de } \\
\text { palabras } \\
\text { diferentes }\end{array}$ & $\begin{array}{c}\text { (\%) } \\
\text { rareza (\%) }\end{array}$ & \\
\hline 1.Ixhuatlán Veracruz & 306 & 119 & 75 & 38.89 & 63.03 \\
\hline 2.Otro origen de residencia & 138 & 61 & 44 & 44.20 & 72.13 \\
\hline
\end{tabular}

Las proporciones de las categorías formadas en la asociación libre de palabras para "Café de Ixhuatlán del Café" para cada campo social se presentan en el Cuadro 3. Al realizar el análisis de k-proporciones se obtuvo que no existe diferencia entre categorías evaluadas por cada campo social lo que sugiere que los significados de compra que los consumidores otorgan al café de Veracruz es indiferente, sin embargo para los consumidores de Veracruz resaltan significados como tradición y proceso.

Cuadro 3. Proporciones de las categorías mencionadas para "Café de Ixhuatlán del Café" por campo social.

\begin{tabular}{lcc}
\hline Categoría & Ixhuatlán, Veracruz & $\begin{array}{c}\text { Otro origen de } \\
\text { residencia }\end{array}$ \\
\hline Hedonismo & $11.30 \mathrm{a}$ & $17.86 \mathrm{a}$ \\
\hline Atributos de calidad & $11.32 \mathrm{a}$ & $14.29 \mathrm{a}$ \\
\hline Alimentos & $5.66 \mathrm{a}$ & $14.29 \mathrm{a}$ \\
Presentación & $11.32 \mathrm{a}$ & $8.93 \mathrm{a}$ \\
Familia & $11.32 \mathrm{a}$ & $8.93 \mathrm{a}$ \\
Tradición & $15.09 \mathrm{a}$ & $12.50 \mathrm{a}$ \\
Proceso & $16.04 \mathrm{a}$ & $10.71 \mathrm{a}$ \\
Valores & $9.43 \mathrm{a}$ & $5.36 \mathrm{a}$ \\
Entorno & $8.49 \mathrm{a}$ & $7.14 \mathrm{a}$ \\
\hline
\end{tabular}

Del Análisis de Componentes Principales se obtuvo la ubicación de los campos sociales y de las categorías, se observa que los campos sociales se encuentran en los cuadrantes del lado derecho; la correlación de los consumidores del campo social 1 (Ixhuatlán, Veracruz) es mayor con las categorías Proceso y tradición; para el campo social 2 (consumidores de otras regiones) le otorgan significados al café de hedonismo y calidad con menor fuerza (Grafico 1).

Gráfico 1 Representación de las categorías y de los campos sociales obtenidos por análisis de componentes principales

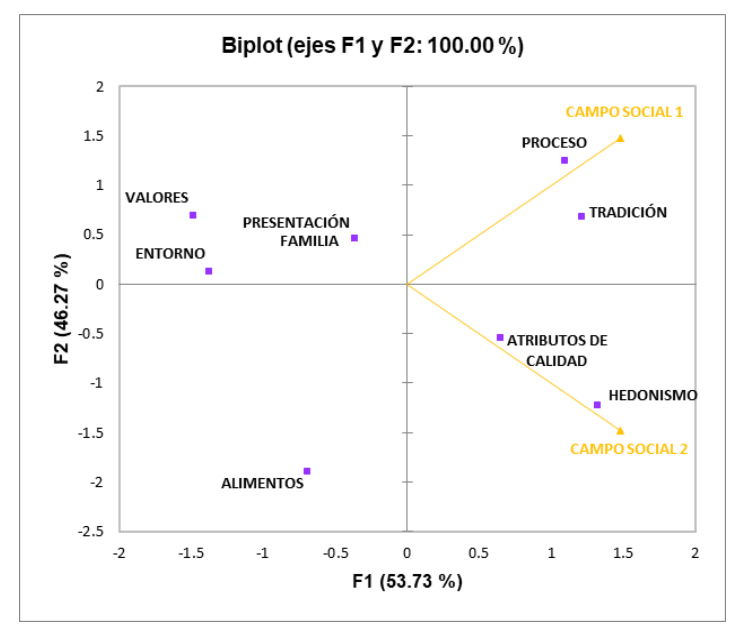


4.2 Disposición a pagar (DAP) un sobreprecio por diferentes tipos de café.

El 80.5\% de los participantes pagarían un sobreprecio por los tipos de café analizados; el 19.5\% no estaría dispuesto a pagar un sobreprecio (cuadro 4). De acuerdo con el análisis, se aprecia que no existe diferencia significativa entre los porcentajes a pagar de acuerdo al tipo de café.

Cuadro 4. Proporciones de consumidores con Disposición a pagar (DAP) un excedente por diferentes tipos de Café.

\begin{tabular}{lccccc}
\hline \multirow{2}{*}{\multicolumn{1}{c}{ Tipo de Café }} & \multicolumn{5}{c}{ Porcentaje extra a pagar } \\
\cline { 2 - 6 } & $\mathbf{0 \%}$ & $\mathbf{5 \%}$ & $\mathbf{1 0} \%$ & $\mathbf{2 0} \%$ & $\mathbf{3 0} \%$ \\
\hline Café con Denominación de Origen & $16.07 \mathrm{a}$ & $22.86 \mathrm{a}$ & $32.50 \mathrm{a}$ & $17.14 \mathrm{a}$ & $11.43 \mathrm{a}$ \\
Café con certificaciones & $26.79 \mathrm{a}$ & $18.57 \mathrm{a}$ & $26.07 \mathrm{a}$ & $19.64 \mathrm{a}$ & $8.93 \mathrm{a}$ \\
\hline Café producido por pequeñas organizaciones & $16.07 \mathrm{a}$ & $26.43 \mathrm{a}$ & $24.29 \mathrm{a}$ & $17.50 \mathrm{a}$ & $15.71 \mathrm{a}$ \\
\hline Café mexicano contra uno extranjero & $18.57 \mathrm{a}$ & $18.93 \mathrm{a}$ & $20.00 \mathrm{a}$ & $22.14 \mathrm{a}$ & $20.36 \mathrm{a}$ \\
\hline Café orgánico & $20.00 \mathrm{a}$ & $21.43 \mathrm{a}$ & $23.21 \mathrm{a}$ & $21.43 \mathrm{a}$ & $13.93 \mathrm{a}$ \\
\hline
\end{tabular}

*Literales diferentes por columna, son diferentes estadísticamente $(p<0.05)$.

Se estimaron los modelos econométricos mediante regresiones logísticas de los tipos de café del cuadro 4. Para el café con denominación de origen, las variables significativas $(\mathrm{p}<0.05)$ fueron la importancia de conocer el origen del café y que tenga sello de indicación geográfica; para el café con certificaciones las variable significativa fue que el café con certificación brinda mayor seguridad; para el café producido por pequeñas organizaciones la variable significativa fue el sabor del café; para el café orgánico lo importante es que cuente con denominación y con premios y certificaciones y la variable que más incidió de manera significativa de un café mexicano con respecto a un extranjero fue que cuente con denominación de origen.

\section{Conclusiones}

La tradición y proceso son los significados de compra más importantes que evocaron esta muestra de consumidores sobre la imagen de café mexicano de Veracruz.

Los atributos de mayor valoración sobre las aseveraciones de café evaluadas están relacionados con el origen del café, los sellos de indicación geográfica y denominación de origen, la certeza que brinda un café con certificaciones y atributos sensoriales como el buen sabor asociado a café de pequeños productores.

La mayor disposición a pagar por los tipos de café evaluados con el mayor número de consumidores (32.5\%) es un $10 \%$ para un café con denominación de origen.

Se concluye que el café mexicano evoca tradición y el consumidor lo asocia con atributos sensoriales positivos si es de pequeños productores y la disposición a pagar esta relacionada directamente con el origen del café. Esta información puede usarse para que los productores de café promuevan el consumo de café.

\section{Bibliografía}

Bernal Valderrama, P. (2020). De la plantacion a la taza. Un acercamiento etnográfico del recorrido del café en la región Coatepec-Xalapa. Centro de Investigaciones y estudios superiores en Antropología Social.

Cameron, T., \& Huppert, D. (1989). OLS versus ML Estimation Values with Payment of Non-market Resource Card Interval Data, 246, 230-246.

Loureiro, M. L., \& Hine, S. (2002). Discovering Niche Markets : A Comparison of Consumer Willingness to Pay for Local ( Colorado Grown ), Organic , and GMO-Free Products, (February). https://doi.org/10.1017/S1074070800009251.

Muñoz-Rodriguez, M., Gómez-Pérez, D., Santoyo-Cortés, V. H., \& Rosales-Lechuga, R. (2019). Los negocios del café ¿Cómo innovar en el contexto de la paradoja del café, en pro de una red de valor más inclusiva y accesible?. México: Universidad Autónoma Chapingo, CIESTAAM.

Ortega Hernández, A., \& Ramírez Valverde, B. (2013). Crisis de la cafeticultura y migración en el contexto de pobreza y marginación. el caso de los productores indígenas de huehuetla, puebla. Ra Ximhai, 
9, 173-186.

Rodrigues, H., Ballester, J., Saenz-navajas, M. P., \& Valentin, D. (2015). Structural approach of social representation: Application to the concept of wine minerality in experts and consumers. FOOD QUALITY AND PREFERENCE, 46, 166-172. https://doi.org/10.1016/j.foodqual.2015.07.019. 